\begin{tabular}{|c|c|c|c|}
\hline \multirow{3}{*}{$\begin{array}{r}\text { Case Reports in } \\
\text { Gastroenterology }\end{array}$} & \multirow{2}{*}{\multicolumn{2}{|c|}{ Case Rep Gastroenterol 2015;9:142-151 }} & \\
\hline & & & \multirow[b]{2}{*}{ Oparger } \\
\hline & $\begin{array}{l}\text { DOI: } 10.1159 / 000430492 \\
\text { Publisnea onine. Trlay } 8,2015\end{array}$ & $\begin{array}{l}\text { ( ) } 2015 \text { S. Karger AG, Basel } \\
1662-0631 / 15 / 0092-0142 \$ 39.50 / 0 \\
\text { www.karger.com/crg }\end{array}$ & \\
\hline & $\begin{array}{l}\text { This is an Open Access artic } \\
\text { Attribution-NonCommercial } 3.0 \\
\text { license), applicable to the onlin } \\
\text { commercial purposes only. }\end{array}$ & $\begin{array}{l}\text { the terms of the Creative Common } \\
\text { (CC BY-NC) (www.karger.com/OA } \\
\text { cle only. Distribution permitted for non }\end{array}$ & \\
\hline
\end{tabular}

\title{
An Atypical Case of Eosinophilic Gastroenteritis Presenting as Hypovolemic Shock
}

\author{
Miguel Martillo Jean Abed ${ }^{a, c} \quad$ Michael Herman $^{a} \quad$ Elie Abed $^{a}$ \\ Wenjing Shi ${ }^{\mathrm{b}}$ Khushboo Munot ${ }^{\mathrm{a}, d}$ Pavan Kumar Mankal ${ }^{\mathrm{a}, \mathrm{d}}$ \\ Rajan Gurunathan ${ }^{a, c}$ Gabriel Ionescu ${ }^{a, d}$ Donald P. Kotler ${ }^{a, d}$ \\ ${ }^{a}$ Department of Medicine, ${ }^{b}$ Department of Pathology, ${ }^{c}$ Division of Hospital Medicine \\ and ${ }^{d}$ Division of Gastroenterology, Mount Sinai St. Luke's and Mount Sinai Roosevelt \\ Hospitals, Icahn School of Medicine, New York, N.Y., USA
}

\section{Key Words}

Eosinophilic gastroenteritis $\cdot$ Hypovolemic shock $\cdot$ Diarrhea $\cdot$ Acute renal failure

\begin{abstract}
Eosinophilic gastroenteritis is an uncommon condition characterized by focal or diffuse infiltration of eosinophils in the gastrointestinal tract in the absence of secondary causes. The pathogenesis of this condition is not well understood and its clinical presentation depends on the segment and layer of the gastrointestinal tract affected. The definition of eosinophilic gastroenteritis may be difficult, as the normal ranges of eosinophil numbers in normal and abnormal gastric and intestinal mucosa are not standardized. We present the case of a 59-year-old male who came to the hospital with hypovolemic shock and lethargy secondary to severe diarrhea. Laboratory analysis was significant for peripheral eosinophilia, and pathology from both the duodenum and colon showed marked eosinophilic infiltration.
\end{abstract}

(c) 2015 S. Karger AG, Basel

\section{Introduction}

Eosinophilic gastroenteritis (EG) is a rare disease characterized by focal or diffuse eosinophilic infiltration of the gastrointestinal tract, in the absence of secondary causes like adrenal insufficiency, medication hypersensitivity reactions, collagen vascular disease, malignancy, hypereosinophilic syndrome or parasitic infection. In 2011, the prevalence of EG in

KARGER 125:s $\quad \begin{aligned} & \text { Jean Abed, MD } \\ & \text { Division of Hospital Medicine } \\ & \text { Mount Sinai St. Luke's and Mount Sinai Roosevelt Hospitals } \\ & \text { 1111 Amsterdam Avenue, New York, NY } 10025 \text { (USA) } \\ & \text { E-Mail jabed@chpnet.org }\end{aligned}$


Martillo et al.: An Atypical Case of Eosinophilic Gastroenteritis Presenting as Hypovolemic Shock

the United States was estimated to be 22-28 per 100,000 persons [1]. EG can affect patients of any age, but it is diagnosed most frequently in the third through fifth decade of life [2-4] and is reported to be more common in men [3]. This condition has been associated with a personal or family history of allergic disorders, such as asthma, hay fever or eczema, which are present in $60-70 \%$ of patients diagnosed with EG [5].

Evidence supports the concept that EG develops as a result of the interplay of genetic and environmental factors. Approximately $10 \%$ of patients who are diagnosed with EG have an immediate family member with this condition [6]. The pathogenesis of this disease has yet not be fully explained, however it is hypothesized to be a polygenic allergic disorder between immunoglobulin E (IgE) and delayed Th2 response, but not fitting completely into either category [7]. A variety of clinical and experimental models support the critical role for allergens, eosinophils, Th2-type cytokines and eotaxin-1 in mediating eosinophilic inflammation [7]. It is suggested that food allergens activate and drive the differentiation of IL-5+ Th2 cells, leading to gut eosinophilia [8,9]. Furthermore, the presence of eotaxin enhances the recruitment of eosinophils into the gastrointestinal tract [9]. Once eosinophils are present in the gut, they are able to persist through the release of eosinophil-active cytokines, such as IL-3, IL-5 and granulocyte-macrophage colony-stimulating factor [10]. In addition to this, eosinophils cause local inflammation by releasing major basic proteins and cytotoxic cationic protein [5].

Patients with EG have a variety of problems, including nausea, vomiting, abdominal pain, diarrhea, weight loss and malabsorption [11-13]. These clinical manifestations may vary by the involved organ and by the layer of tissue targeted by the infiltrative process $[2$, 14]. The diagnosis is established by demonstrating eosinophilic infiltration on biopsies obtained on endoscopy, laparoscopy or laparotomy. Multiple biopsies may be required because of the patchy nature of the disease [15]. We present the case of a male patient with EG who presented with severe diarrhea, acute renal failure and hypovolemic shock.

\section{Case Report}

A 59-year-old male with a past medical history significant for obesity status post gastric bypass surgery, hypertension and hyperlipidemia was admitted to the hospital with multiple episodes of diarrhea for the last 6 days which had started in Australia prior to his arrival to New York City for his vacation. He described the diarrhea as large-volume and watery with more than 15 episodes per day, with no similar episodes in the past. There was no complaint of abdominal pain, fevers and chills and no evidence of mucus or blood in the stool. He denied any prior recent trip when he was in Australia. In addition to denying a personal or family history of colon or small bowel malignancy, he also denied consuming alcohol, smoking and illicit drug use. He had no known allergies and his home medications included only olmesartan and simvastatin. Before presenting to the hospital, he had been prescribed erythromycin for his diarrhea which he took for 2 days, and subsequently it had been switched to ciprofloxacin for 1 day without any relief.

On admission he was in hypovolemic shock, with hypotension and lethargy. His physical examination was notable for dry mucous membranes, whereas his cardiovascular, respiratory and gastrointestinal examination was unremarkable. He was found to have severe dehydration, electrolyte abnormalities and acute kidney insufficiency. His initial laboratory results were remarkable for a BUN of $56 \mathrm{mg} / \mathrm{dl}$ and a creatinine level of $7.30 \mathrm{mg} / \mathrm{dl}$. His complete blood count was notable for white blood cells of $29,600 / \mu \mathrm{l}$ and hemoglobin of $17.8 \mathrm{gm} / \mathrm{dl}$, platelets of $322,000 / \mu \mathrm{l}$ and eosinophilia of $14 \%$ (absolute eosinophil count 4.0). 
Martillo et al.: An Atypical Case of Eosinophilic Gastroenteritis Presenting as Hypovolemic Shock

His liver function panel showed mild hypoalbuminemia of $3.5 \mathrm{gm} / \mathrm{dl}$ (table 1, table 2). Additionally, the patient had negative white blood cells in his stools, four negative stool studies for ova and parasites and negative stool cultures. More specifically, Vibrio cholerae test and Clostridium difficile toxin were negative. His HIV test was nonreactive and thyroid-stimulating hormone, gastrin, somatostatin and vasoactive intestinal peptide levels were within normal limit.

During the hospital course his daily laboratory tests were remarkable for constant leukocytosis with eosinophil predominance (ranging between 14 and 31\%). His IgE serum level was 1,534 . He had an abdominal computed tomography scan that showed mild dilation and thickening of the proximal jejunum with incidental transient intussusceptions reflecting altered motility (fig. 1).

The patient received aggressive intravenous hydration with electrolyte repletion. His lethargy resolved and blood pressure improved. His kidney function significantly improved over the hospital course; however, he continued to have several episodes of watery diarrhea every day. On the third day of hospitalization he had a colonoscopy which showed a semisessile 15-mm polyp localized in the descending colon which was removed with a hot snare; the rest of the colon mucosa appeared to be normal, with no evidence of erythema or ulceration, and random biopsies were obtained. The patient also underwent esophagogastroduodenoscopy, which revealed a normal esophagus with vertically banded gastroplasty, nodular gastroesophageal junction and erythematous mucosa in the pylorus (fig. 2, fig. 3).

The pathology report (fig. 4) demonstrated markedly increased eosinophils in the lamina propria ( $>40 /$ high-power field [HPF]) of the duodenum, stomach and colon. The duodenal aspirate was negative for parasites. Subsequently, the diagnosis of EG was made. The diarrhea started to improve and resolved by day 10 of hospitalization; his kidney function returned back to normal. The treatment was mainly supportive care, consisting of intravenous fluids and electrolytes repletion. He was discharged on day 10 to resume the rest of his vacation.

\section{Discussion}

EG is a rare inflammatory condition which may affect the entire gastrointestinal tract from the esophagus to the colon and where eosinophils are present in excess of 20/HPF in either the mucosal, muscular or subserosal layers $[2,16]$. The clinical manifestations depend on the affected region of the gastrointestinal tract [14]. For example, with gastric and colonic mucosal disease, the most common symptoms are abdominal pain, nausea, vomiting, early satiety and diarrhea [2]. In contrast, dominant duodenal disease may present with malabsorption, protein-losing enteropathy and failure to thrive. Additionally, the extent of invasion of the eosinophils into the various layers can affect presentation. For instance, eosinophilic invasion of the muscular layer causes muscular wall thickening and impaired motility causing intestinal obstruction, leading to nausea, vomiting and abdominal pain and, in severe cases, perforation or obstruction of the gastric outlet, small bowel or colon [2]. Patients with subserosal EG can suffer from isolated ascites, causing abdominal distention and discomfort. In our case, eosinophils were more predominant in the mucosa of the stomach, duodenum and colon, which usually manifests with diarrhea. In the abdominal computed tomography we visualized mild thickening and dilation of the jejunal folds; since jejunal and ileal biopsies are not routinely obtained on endoscopy, we do not known how much these gut segments contributed to the patient's presentation. 
Martillo et al.: An Atypical Case of Eosinophilic Gastroenteritis Presenting as Hypovolemic Shock

Severe diarrhea and gastrointestinal enteropathy have recently been recognized as an adverse effect of the angiotensin II receptor antagonist olmesartan $[17,18]$. The first case series to describe an association included 22 patients with enteropathy refractory to standard therapy interventions but who responded to discontinuation of olmesartan. Similar to our case, those patients presented with severe diarrhea leading to hospitalization and hemodynamic deterioration. However, in those patients the pathology material revealed increased intraepithelial lymphocytes, villous atrophy and subepithelial collagen deposition most consistent with a sprue-like condition [17-20].

The pathogenesis of EG is not well understood. In general, patients with EG have elevated serum IgE and an allergy component has often been suggested as a possible etiology [21]. Several studies have shown an improvement in disease with changes in the patient's diet [22-25]. The hypothesis is that exposure of patients to foods they are allergic to can cause activation of interleukins that express allergen-specific T helper cells in EG, leading to intestinal eosinophilia [8].

Patient with EG may have various significant laboratory findings. Serum eosinophil counts are usually elevated, but can be normal in approximately $20 \%$ of patients, and counts are usually higher in patients with mucosal and subserosal EG [26]. D-Xylose test can be abnormal in mucosal EG because of carbohydrate malabsorption [14]. Additionally, patients with mucosal disease may present with hypoalbuminemia secondary to protein-losing enteropathy, associated with increased mucosal permeability [27]. Eosinophilic EG can also cause anemia due to impaired iron absorption when the duodenal mucosal layer is involved [27].

The diagnosis of EG is based on the presence of eosinophils in a gastrointestinal tract biopsy or ascitic fluid. Before suspecting a diagnosis of EG, other etiologies of eosinophilia need to be excluded, such as parasites (Ancylostoma, Anisakis, Strongyloides, Toxocara, Trichiura and Trichinella), medications (antimalarials, penicillins, cephalosporins, sulfonamides, tetracyclines, nitrofurantoin, angiotensin-converting enzyme inhibitors, antituberculosis therapies, anticonvulsants, nonsteroidal anti-inflammatory drugs, proton pump inhibitors, $\mathrm{H}_{2}$ receptor antagonists and chlorpropamide) [28], dietary and herbal supplements, ingestions of raw or undercooked meat and a history of residing in or traveling to parasiteendemic areas. Stool and serologic studies should be collected and should include microscopy for ova and parasites and serologies for Strongyloides and Toxocara species, to exclude parasitic infections as a secondary cause of eosinophilic EG [2].

Endoscopically, mucosal disease can appear relatively nonspecific with nodularity, polypoid gastric mucosa, erythema or erosions, therefore the diagnosis is made histologically. Because of the nonspecific nature of mucosal disease, biopsies should be taken from both normal- and abnormal-appearing mucosa, as normal-appearing mucosa can also have eosinophilic infiltration [29]. The diagnosis of EG is made by the presence of more than the number of expected eosinophils seen on a random gastrointestinal tract biopsy [30]. While there is not a designated cutoff number of eosinophils to make a diagnosis, most reports have defined EG when there are $>20$ eosinophils/HPF $[2,31,32]$. However, an experienced gastrointestinal pathologist should always analyze the specimens to assess whether the number of eosinophils is greater than expected in the tissue biopsy [30]. Our patient had $>40$ eosinophils/HPF visualized in the lamina propria from the stomach, duodenum and colonic mucosa. Patients with mucosal biopsies who have excluded mucosal disease but still present with gastrointestinal symptoms may need to undergo laparoscopic full-thickness biopsy as mucosal biopsy alone cannot rule out muscular or subserosal EG $[2,14]$.

Initial treatment begins with diet modification in an attempt to eliminate potential food allergens [24]. If dietary changes do not improve symptoms or patients experience recurrent 
Martillo et al.: An Atypical Case of Eosinophilic Gastroenteritis Presenting as Hypovolemic Shock

symptoms or flares, a short to long course of prednisone should be initiated, depending on the severity of the patient's symptoms [33].

\section{Author Contributions}

M. Martillo and M. Herman wrote the manuscript; J. Abed and P.K. Mankal reviewed and edited the manuscript; K. Munot provided the esophagogastroduodenoscopy/colonoscopy images; E. Abed edited the images and contributed to the manuscript; W. Shi provided the pathology images; R. Gurunathan, G. Ionescu and D.P. Kotler reviewed the manuscript.

\section{Statement of Ethics}

The patient gave his verbal consent for publication of this case report. It is documented in his electronic medical record.

\section{Disclosure Statement}

The authors have no conflicts of interest or financial disclosures to report.

\section{References}

1 Spergel JM, Book WM, Mays E, Song L, Shah SS, Talley NJ, Bonis PA: Variation in prevalence, diagnostic criteria, and initial management options for eosinophilic gastrointestinal diseases in the United States. J Pediatr Gastroenterol Nutr 2011;52:300-306.

-2 Talley NJ, Shorter RG, Phillips SF, Zinsmeister AR: Eosinophilic gastroenteritis: a clinicopathological study of patients with disease of the mucosa, muscle layer, and subserosal tissues. Gut 1990;31:54-58.

-3 Chen MJ, Chu CH, Lin SC, Shih SC, Wang TE: Eosinophilic gastroenteritis: clinical experience with 15 patients. World J Gastroenterol 2003;9:2813-2816.

4 Venkataraman S, Ramakrishna BS, Mathan M, Chacko A, Chandy G, Kurian G, Mathan VI: Eosinophilic gastroenteritis - an Indian experience. Indian J Gastroenterol 1998;17:148-149.

-5 Rothenberg ME: Eosinophilic gastrointestinal disorders (EGID). J Allergy Clin Immunol 2004;113:11-28; quiz 29.

-6 Guajardo JR, Plotnick LM, Fende JM, Collins MH, Putnam PE, Rothenberg ME: Eosinophil-associated gastrointestinal disorders: a world-wide-web based registry. J Pediatr 2002;141:576-581.

7 Khan S, Orenstein SR: Eosinophilic gastroenteritis. Gastroenterol Clin North Am 2008;37:333-348,v.

-8 Prussin C, Lee J, Foster B: Eosinophilic gastrointestinal disease and peanut allergy are alternatively associated with IL-5+ and IL-5(-) T(H)2 responses. J Allergy Clin Immunol 2009;124:1326-1332.e6.

-9 Hogan SP, Mishra A, Brandt EB, Foster PS, Rothenberg ME: A critical role for eotaxin in experimental oral antigen-induced eosinophilic gastrointestinal allergy. Proc Natl Acad Sci USA 2000;97:6681-6686.

-10 Desreumaux P, Bloget F, Seguy D, Capron M, Cortot A, Colombel JF, Janin A: Interleukin 3, granulocytemacrophage colony-stimulating factor, and interleukin 5 in eosinophilic gastroenteritis. Gastroenterology 1996;110:768-774.

11 Oh HE, Chetty R: Eosinophilic gastroenteritis: a review. J Gastroenterol 2008;43:741-750.

12 Freeman HJ: Adult eosinophilic gastroenteritis and hypereosinophilic syndromes. World J Gastroenterol 2008;14:6771-6773.

-13 Mueller S: Classification of eosinophilic gastrointestinal diseases. Best Pract Res Clin Gastroenterol 2008;22: 425-440.

Klein NC, Hargrove RL, Sleisenger MH, Jeffries GH: Eosinophilic gastroenteritis. Medicine 1970;49:299-319. Khan S: Eosinophilic gastroenteritis. Best Pract Res Clin Gastroenterol 2005;19:177-198.

Matsushita M, Hajiro K, Morita Y, Takakuwa H, Suzaki T: Eosinophilic gastroenteritis involving the entire digestive tract. Am J Gastroenterol 1995;90:1868-1870. 
Martillo et al.: An Atypical Case of Eosinophilic Gastroenteritis Presenting as Hypovolemic Shock

17 Hartranft ME, Regal RE: 'Triple phase' budesonide capsules for the treatment of olmesartan-induced enteropathy. Ann Pharmacother 2014;48:1234-1237.

18 Rubio-Tapia A, Herman ML, Ludvigsson JF, Kelly DG, Mangan TF, Wu TT, Murray JA: Severe spruelike enteropathy associated with olmesartan. Mayo Clin Proc 2012;87:732-738.

19 Dreifuss SE, Tomizawa Y, Farber NJ, Davison JM, Sohnen AE: Spruelike enteropathy associated with olmesartan: an unusual case of severe diarrhea. Case Rep Gastrointest Med 2013;2013:618071.

20 Gaur V, Albeldawi M, Weber L: Chronic diarrhea and weight loss. Gastroenterology 2014;146:347.

21 Caldwell JH, Tennenbaum JI, Bronstein HA: Serum IgE in eosinophilic gastroenteritis. Response to intestinal challenge in two cases. New Engl J Med 1975;292:1388-1390.

22 Justinich C, Katz A, Gurbindo C, Lepage G, Chad Z, Bouthillier L, Seidman E: Elemental diet improves steroiddependent eosinophilic gastroenteritis and reverses growth failure. J Pediatr Gastroenterol Nutr 1996;23: 81-85.

23 Chehade M, Sicherer SH, Magid MS, Rosenberg HK, Morotti RA: Multiple exudative ulcers and pseudopolyps in allergic eosinophilic gastroenteritis that responded to dietary therapy. J Pediatr Gastroenterol Nutr 2007;45:354-357.

-24 Spergel JM, Shuker M: Nutritional management of eosinophilic esophagitis. Gastrointest Endosc Clin N Am 2008;18:179-194, xi.

25 Talley NJ: Gut eosinophilia in food allergy and systemic and autoimmune diseases. Gastroenterol Clin North Am 2008;37:307-332, v.

26 Chang JY, Choung RS, Lee RM, Locke GR 3rd, Schleck CD, Zinsmeister AR, Smyrk TC, Talley NJ: A shift in the clinical spectrum of eosinophilic gastroenteritis toward the mucosal disease type. Clin Gastroenterol Hepatol 2010;8:669-675, quiz e88.

27 Chehade M, Magid MS, Mofidi S, Nowak-Wegrzyn A, Sampson HA, Sicherer SH: Allergic eosinophilic gastroenteritis with protein-losing enteropathy: intestinal pathology, clinical course, and long-term followup. J Pediatr Gastroenterol Nutr 2006;42:516-521.

28 Maidment I, Williams C: Drug-induced eosinophilia. Pharm J, January 82000. http://www.pharmaceutical-journal.com/learning/learning-article/drug-induced-eosinophilia/ 20000049.article.

29 Lee CM, Changchien CS, Chen PC, Lin DY, Sheen IS, Wang CS, Tai DI, Sheen-Chen SM, Chen WJ, Wu CS: Eosinophilic gastroenteritis: 10 years experience. Am J Gastroenterol 1993;88:70-74.

30 Lee M, Hodges WG, Huggins TL, Lee EL: Eosinophilic gastroenteritis. South Med J 1996;89:189-194.

-31 Reed C, Woosley JT, Dellon ES: Clinical characteristics, treatment outcomes, and resource utilization in children and adults with eosinophilic gastroenteritis. Dig Liver Dis 2015;47:197-201.

32 Hurrell JM, Genta RM, Melton SD: Histopathologic diagnosis of eosinophilic conditions in the gastrointestinal tract. Adv Anat Pathol 2011;18:335-348.

-33 Cello JP: Eosinophilic gastroenteritis - a complex disease entity. Am J Med 1979;67:1097-1104. 
Martillo et al.: An Atypical Case of Eosinophilic Gastroenteritis Presenting as Hypovolemic Shock

Table 1. Laboratory results: chemistry and hematology

\begin{tabular}{|c|c|c|c|c|c|c|c|c|}
\hline & Reference range & Day 1 & Day 2 & Day 3 & Day 4 & Day 5 & Day 6 & Day 7 \\
\hline \multicolumn{9}{|l|}{ Chemistry } \\
\hline Sodium & $136-146 \mathrm{mmol} / \mathrm{l}$ & 138 & 143 & 144 & 139 & 142 & 142 & 136 \\
\hline Potassium & $3.5-5.1 \mathrm{mmol} / \mathrm{l}$ & 3.4 & 3.5 & 3.7 & 3.0 & 4.0 & 3.6 & 3.7 \\
\hline Chloride & 98-107 mmol/l & 111 & 112 & 113 & 113 & 114 & 114 & 108 \\
\hline $\mathrm{CO}_{2}$ & $22-30 \mathrm{mmol} / \mathrm{l}$ & 14 & 21 & 19 & 20 & 21 & 20 & 21 \\
\hline BUN & $8-24 \mathrm{mg} / \mathrm{dl}$ & 50 & 46 & 31 & 17 & 10 & 7 & 7 \\
\hline Creatinine & $0.66-1.25 \mathrm{mg} / \mathrm{dl}$ & 5.7 & 4.20 & 2.10 & 1.30 & 1.10 & 1.00 & 1.00 \\
\hline Glucose & $74-106 \mathrm{mg} / \mathrm{dl}$ & 95 & 94 & 84 & 79 & 74 & 73 & 69 \\
\hline Est. GFR & & 10 & 15 & 32 & 57 & 69 & 76 & 76 \\
\hline Anion gap & $7-16 \mathrm{mmol} / \mathrm{l}$ & 13 & 10 & 12 & 6 & 7 & 8 & 7 \\
\hline Magnesium & $1.6-2.3 \mathrm{mg} / \mathrm{dl}$ & 2.0 & 1.9 & 1.9 & - & 1.7 & 1.6 & 1.6 \\
\hline Calcium & $8.4-10.3 \mathrm{mg} / \mathrm{dl}$ & 7.4 & 8.0 & 8.2 & 7.9 & 8.5 & 8.3 & 8.4 \\
\hline Phosphorus & $2.5-4.5 \mathrm{mg} / \mathrm{dl}$ & 10.2 & 4.6 & - & - & - & 2.9 & - \\
\hline \multicolumn{9}{|l|}{ Endocrinology } \\
\hline TSH & $0.55-4.78 \mathrm{mIU} / \mathrm{ml}$ & & & & & & & 1 \\
\hline Gastrin & $\leq 100 \mathrm{pg} / \mathrm{ml}$ & & & & & & & 74 \\
\hline VIP & $20-42 \mathrm{pg} / \mathrm{ml}$ & & & & & & & 36 \\
\hline \multicolumn{9}{|l|}{ Hematology } \\
\hline WBC & $3.9-9.8 \mathrm{~K} / \mu \mathrm{l}$ & 26.9 & 19.7 & 22.5 & 20.1 & 19.4 & 19.3 & 16.1 \\
\hline Hemoglobin & $13.0-17.0 \mathrm{~g} / \mathrm{dl}$ & 14.9 & 13.9 & 14.1 & 12.7 & 12.8 & 12.2 & 12.9 \\
\hline Hematocrit & $38.0-51.0 \%$ & 43.9 & 41.4 & 41.1 & 38.5 & 38.5 & 36.2 & 38.7 \\
\hline Platelet count & $150-450 \mathrm{~K} / \mu \mathrm{l}$ & 264 & 246 & 233 & 212 & 225 & 196 & 174 \\
\hline $\mathrm{RBC}$ & $4.20-5.60$ & 4.86 & 4.53 & 4.49 & 4.22 & 4.15 & 3.94 & 4.10 \\
\hline Basophils automated & $0.1-1.4 \%$ & 0.4 & 0.5 & 0.6 & 0.3 & 0.4 & 0.7 & 0.9 \\
\hline Eosinophils automated & $0.7-8.0 \%$ & 14.9 & 20.1 & 19.5 & 25.7 & 26.4 & 31.2 & 21.1 \\
\hline Lymphocytes automated & $18.0-44.0 \%$ & 16.4 & 20.1 & 22.9 & 22.6 & 22.0 & 21.5 & 20.8 \\
\hline Monocytes automated & $4.0-9.0 \%$ & 3.8 & 3.8 & 5.5 & 4.2 & 4.2 & 4.0 & 4.3 \\
\hline Neutrophils automated & $40.0-74.0 \%$ & 64.5 & 55.5 & 51.5 & 47.2 & 47.2 & 42.6 & 52.9 \\
\hline Sedimentation rate & $0-13 \mathrm{~mm} / \mathrm{h}$ & & & 7 & & & & \\
\hline
\end{tabular}

Bold values indicate markedly elevated eosinophils seen in eosinophilic gastroenteritis. 


\section{Case Reports in \\ Gastroenterology}

\begin{tabular}{l|l}
\hline \multicolumn{2}{l}{ Case Rep Gastroenterol 2015;9:142-151 } \\
\hline DOI: 10.1159/000430492 & $\begin{array}{l}\text { @ 2015 S. Karger AG, Basel } \\
\text { www.karger.com/crg }\end{array}$ \\
\hline
\end{tabular}

Martillo et al.: An Atypical Case of Eosinophilic Gastroenteritis Presenting as Hypovolemic Shock

Table 2. Laboratory results: immunology

\begin{tabular}{lll}
\hline Immunology & Reference range & Serum values \\
\hline IgA, serum & $70-400 \mathrm{mg} / \mathrm{dl}$ & 271 \\
IgM, serum & $40-230 \mathrm{mg} / \mathrm{dl}$ & 54 \\
Gliadin Ab IgG & $<20 \mathrm{U}$ & 2 \\
Gliadin Ab IgA & $<20 \mathrm{U}$ & 4 \\
IgE, serum & $\leq \mathbf{1 1 4} \mathbf{0 0 0} \mathbf{~ U / l}$ & $\mathbf{1 , 5 3 4}$ \\
IgG subclass 4 & $4.0-86.0 \mathrm{mg} / \mathrm{dl}$ & 80.9 \\
IgG subclass 3 & $22-178 \mathrm{mg} / \mathrm{dl}$ & 15 \\
IgG subclass 2 & $241-700 \mathrm{mg} / \mathrm{dl}$ & 366 \\
IgG subclass 1 & $382-929 \mathrm{mg} / \mathrm{dl}$ & 519 \\
TTG Ab IgA & $<4 \mathrm{U} / \mathrm{ml}$ & 1 \\
\hline
\end{tabular}

Bold values indicate elevated IgE seen in eosinophilic gastroenteritis.
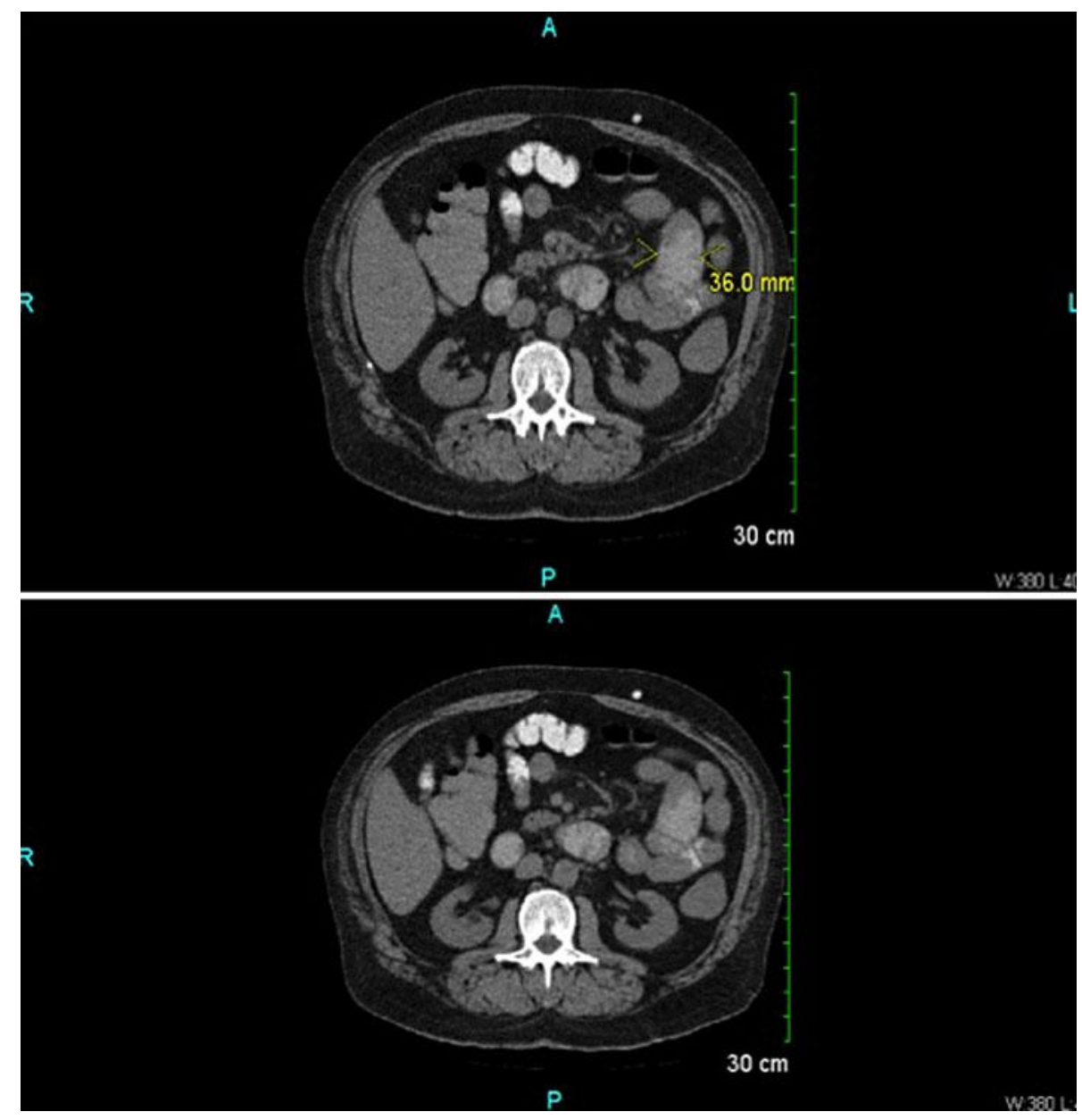

Fig. 1. Proximal jejunal dilation (up to $36 \mathrm{~mm}$ in diameter) and mucosal thickening and possibly transient intussusception in the proximal jejunum (nonobstructing). 


\begin{tabular}{rl|l} 
Case Reports in & \multicolumn{2}{l}{} \\
\cline { 2 - 3 } Gastroenterology & \multicolumn{2}{l}{ Case Rep Gastroenterol 2015;9:142-151 } \\
\cline { 2 - 3 } & DOI: 10.1159/000430492 & $\begin{array}{l}\text { @ 2015 S. Karger AG, Basel } \\
\text { www.karger.com/crg }\end{array}$ \\
\cline { 2 - 3 } & Martillo et al.: An Atypical Case of Eosinophilic Gastroenteritis Presenting as
\end{tabular}

Martillo et al.: An Atypical Case of Eosinophilic Gastroenteritis Presenting as Hypovolemic Shock

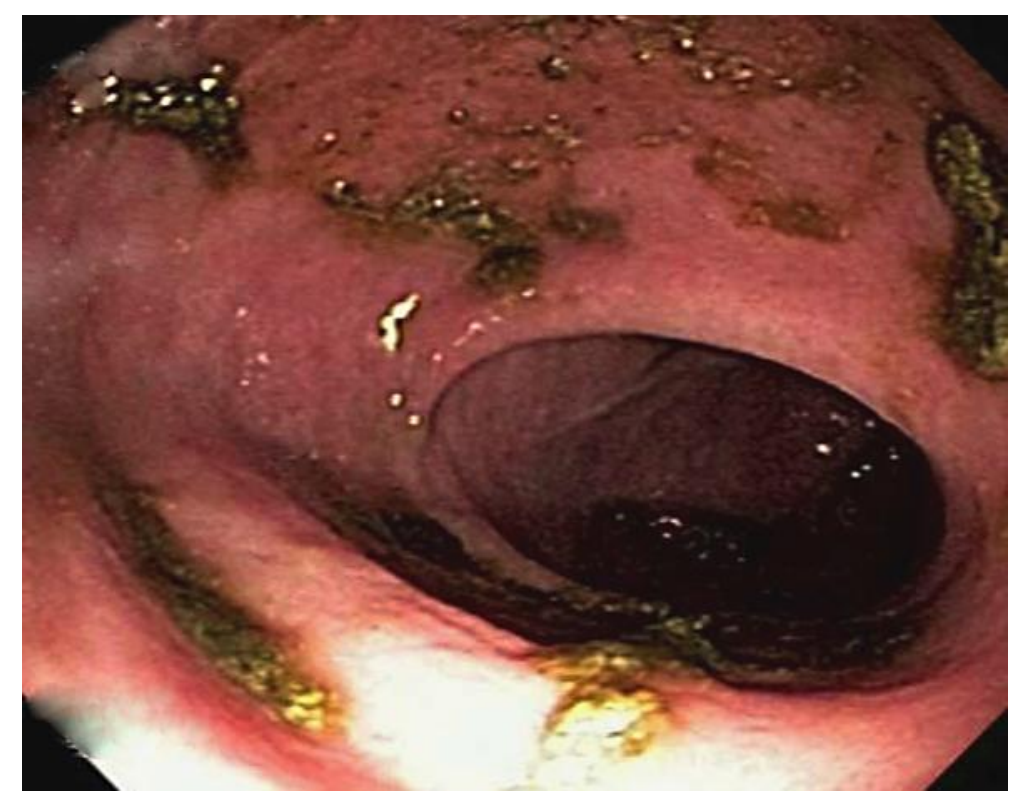

Fig. 2. Normal colon mucosa with no evidence of erythema or ulceration.

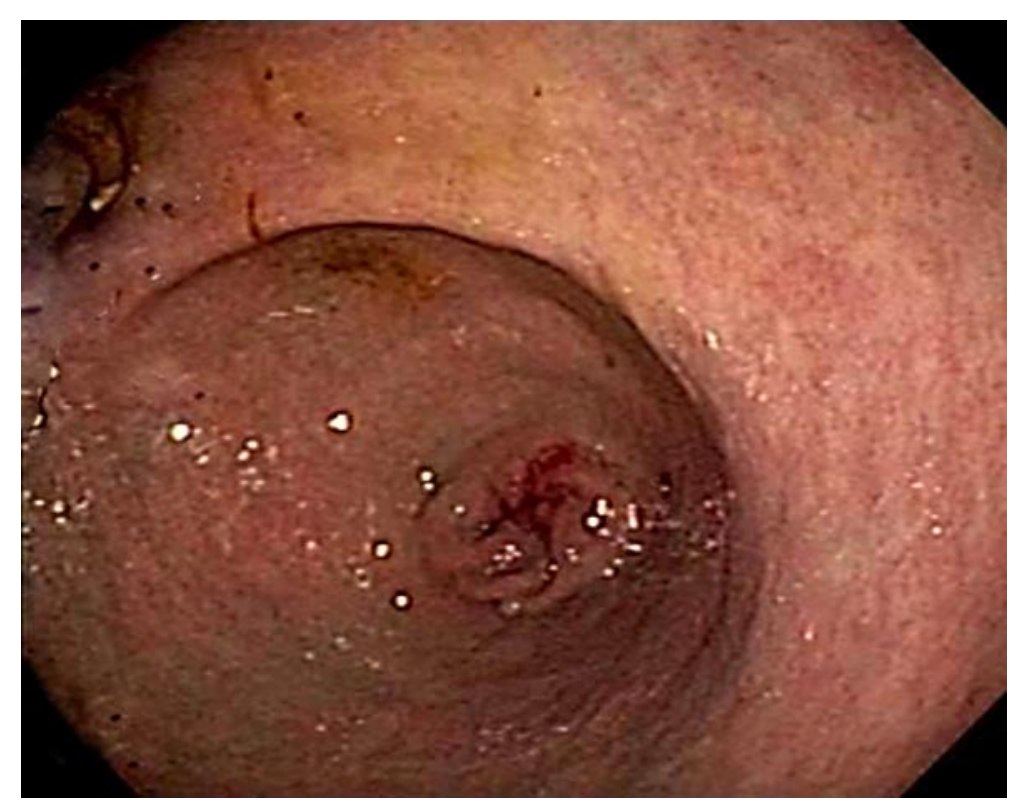

Fig. 3. Erythematous mucosa in the pylorus of the stomach. 


\begin{tabular}{rl|l} 
Case Reports in & \multicolumn{2}{l}{ Case Rep Gastroenterol 2015;9:142-151 } \\
\cline { 2 - 3 } Gastroenterology & DOI: 10.1159/000430492 & $\begin{array}{l}\text { ○ 2015 S. Karger AG, Basel } \\
\text { www.karger.com/crg }\end{array}$ \\
\cline { 2 - 3 }
\end{tabular}

Martillo et al.: An Atypical Case of Eosinophilic Gastroenteritis Presenting as Hypovolemic Shock

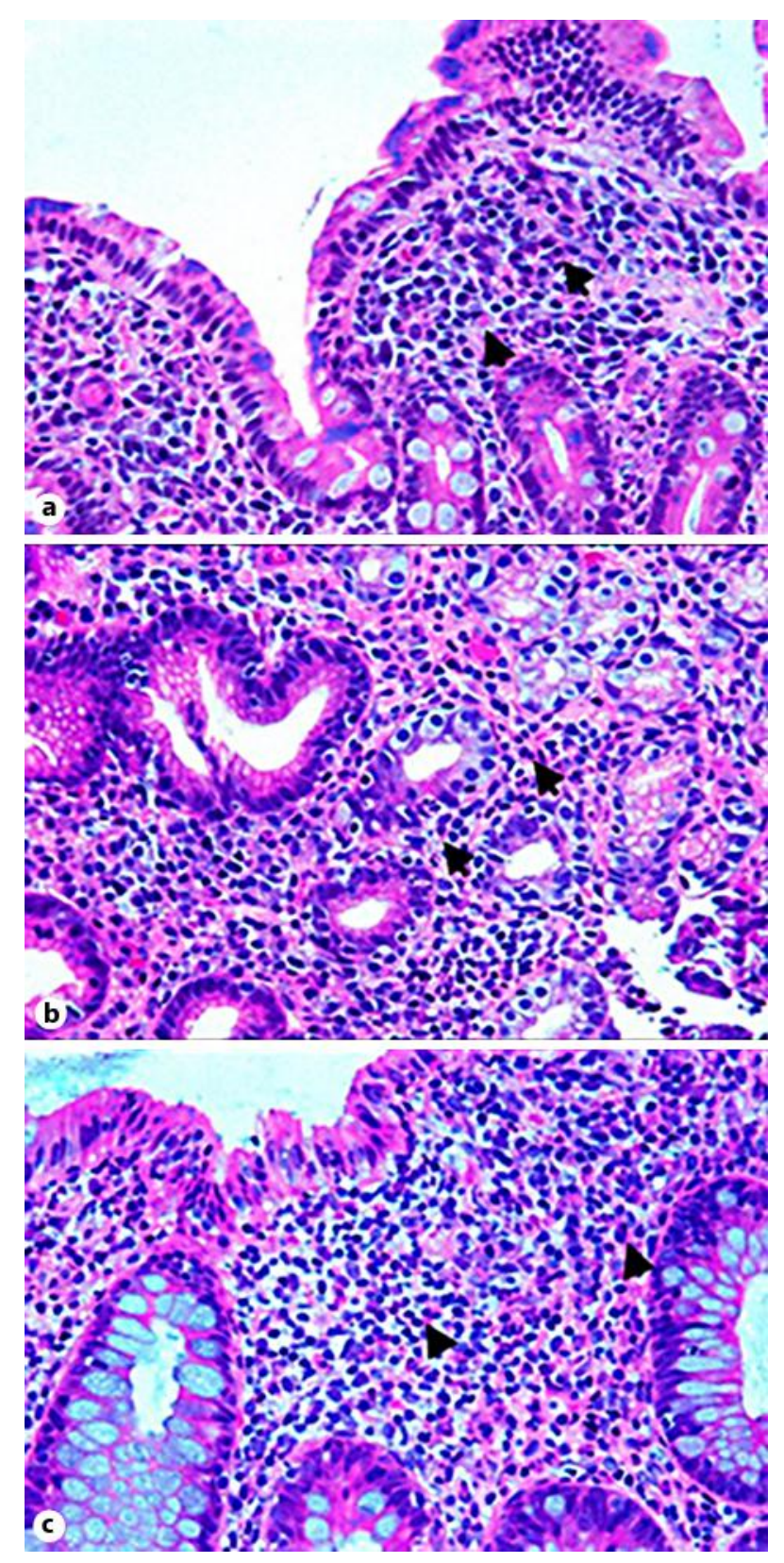

Fig. 4. Markedly increased eosinophils (arrows) in the lamina propria of the duodenum (a), stomach (b) and colon (c) (hematoxylin and eosin; magnification $\times 400$ ). 